\title{
Pharmacology, Part 2: Introduction to Pharmacokinetics
}

\author{
Geoffrey M. Currie \\ Faculty of Science, Charles Sturt University, Wagga Wagga, New South Wales, Australia, and Regis University, Boston, Massachusetts
}

CE credit: For CE credit, you can access the test for this article, as well as additional JNMT CE tests, online at https://www.snmmilearningcenter.org. Complete the test online no later than September 2021. Your online test will be scored immediately. You may make 3 attempts to pass the test and must answer $80 \%$ of the questions correctly to receive $1.0 \mathrm{CEH}$ (Continuing Education Hour) credit. SNMMI members will have their CEH credit added to their VOICE transcript automatically; nonmembers will be able to print out a CE certificate upon successfully completing the test. The online test is free to SNMMI members; nonmembers must pay $\$ 15.00$ by credit card when logging onto the website to take the test.

Pharmacology principles provide a key understanding that underpins the clinical and research roles of nuclear medicine practitioners. This article is the second in a series of articles that aims to enhance the understanding of pharmacologic principles relevant to nuclear medicine. This article will build on the introductory concepts, terminology, and principles of pharmacodynamics explored in the first article in the series. Specifically, this article will focus on the basic principles associated with pharmacokinetics. Article 3 will outline pharmacology relevant to pharmaceutical interventions and adjunctive medications used in general nuclear medicine; article 4, pharmacology relevant to pharmaceutical interventions and adjunctive medications used in nuclear cardiology; article 5, pharmacology relevant to contrast media associated with $\mathrm{CT}$ and $\mathrm{MRI}$; and article 6, drugs in the emergency cart.

Key Words: drug safety; drug metabolism; medication; pharmacokinetics; pharmacology

J Nucl Med Technol 2018; 46:221-230

DOI: 10.2967/jnmt.117.199638

\section{A}

s previously outlined (1), pharmacology is the scientific study of the action and effects of drugs on living systems and the interaction of drugs with living systems (1-7). For general purposes, pharmacology is divided into pharmacodynamics and pharmacokinetics (Fig. 1). The principle of pharmacokinetics is captured by the philosophy of Paracelsus (medieval alchemist): "only the dose makes the poison" $(1,8,9)$. Therapeutic benefits are gained from a drug within a window below which there is no therapeutic benefit and above which there are harmful effects (toxicity). The narrow therapeutic range of some drugs means that only small variations in blood concentration are necessary to result in toxicity (or no effect). Key to maintaining drug concentrations

\footnotetext{
Received Jan. 18, 2018; revision accepted Apr. 5, 2018.

For correspondence or reprints contact: Geoffrey M. Currie, Faculty of Science, Locked Bag 588, Charles Sturt University, Wagga Wagga 2678, Australia.

E-mail: gcurrie@csu.edu.au

Published online May 3, 2018

COPYRIGHT (c) 2018 by the Society of Nuclear Medicine and Molecular Imaging.
}

within the therapeutic range is bioavailability, and factors that may influence bioavailability are an essential aspect of pharmacokinetics. Pharmacokinetics provides a valuable insight into the biologic behavior of interventional and adjunctive medications for the nuclear medicine patient and for the radiopharmaceuticals administered to them. This consideration is especially important in nuclear medicine because both age (the mean age of nuclear medicine patients tends to exceed $60 \mathrm{y}$ ) and disease can have a significant impact on drug or radiopharmaceutical bioavailability, pharmacologic response, drug sensitivity, and drug interactions (9-12).

For a drug to have an effect, excepting by intravenous or intraarterial administration, it must navigate at least one membrane (Fig. 2A). To enter general circulation from the site of administration, and in some cases to get to the site of action (3), a drug may need to overcome physical, chemical, or biologic barriers such as the blood-brain barrier (6). There are different mechanisms by which a drug is transported across a biologic membrane (3). Passive (simple) diffusion requires a degree of lipid solubility to cross the phospholipid bilayer and moves using the concentration gradient until equilibrium is reached. Facilitated diffusion requires no energy, nor can it move against a concentration gradient, but the drug sufficiently resembles the natural ligand to bind to the carrier macromolecule and traverse the membrane. Active transport also capitalizes on the drug's resemblance to the natural ligand, allowing it to bind to carrier macromolecules; however, this process uses energy to transport a drug against the concentration gradient. Other carrier-mediated transport mechanisms exist that are nonspecific drug transporters, such as P-glycoprotein. Pinocytosis incorporates the drug into a lipid vesicle for carrier-mediated transport into the cell cytoplasm. Transport through pores or ion channels can occur with the concentration gradient for small water-soluble drugs.

Pharmacokinetics is essentially the study of the absorption, distribution, metabolism, and excretion of drugs (1-7); that is, how the body affects the drug (Fig. 2B). It is, however, also the study of associated toxicity (1-6). The scope of pharmacokinetics is not limited to healthy subjects but includes variations in bioavailability, physiologic or pathologic conditions, disease-related dose adjustment, and drug 


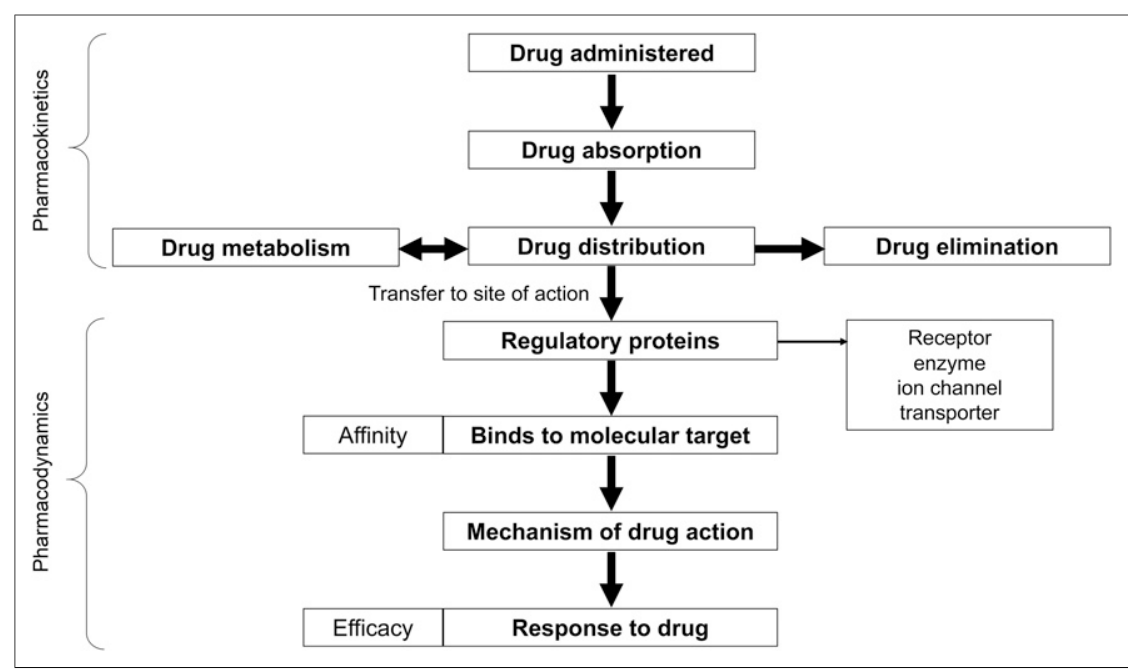

FIGURE 1. Schematic of relationship between pharmacokinetics and pharmacodynamics (1).

interactions (1-7). Combined, these aspects of pharmacokinetics allow customization of drug dosage regimes to enhance outcomes (1-7).

\section{ABSORPTION}

Absorption is the transportation of the drug from the site of administration to the general circulation (2-6). Absorption and the factors that may impede it directly affect drug bioavailability. Bioavailability in the context of pharmacokinetics is the fraction of the administered drug that reaches the systemic circulation (2-6). Clearly, intravenous and intraarterial injection transfers the drug directly into the general circulation and provides $100 \%$ bioavailability. This assumes drugs reach the site of action directly from systemic circulation. Drugs requiring metabolism before action, even with intravenous administration, may have bioavailability less than $100 \%$. Orally (enterally) administered medication is the simplest and most common route but may have variable bioavailability depending on many factors that influence drug absorption, including molecular size of the drug, lipid solubility of the drug, degree of ionization of the drug, dosage form (e.g., tablet or solution), chemical nature of the drug, whether there is complex formation, pharmacologic effect of the dose and concentration of the drug, blood flow (at the site of administration), site of absorption, and route of administration (Table 1).

Generally speaking, the common routes of drug administration can be categorized as oral, membranal, injectional, and transdermal (2-6). Oral administration is simple, convenient, and painless, allowing self-administration of drugs in easily handled forms. Gastrointestinal absorption means that the drug is transported via the portal system to the liver and undergoes first-pass metabolism. First-pass metabolism may render some of the drug inactive, decreasing bioavailability.

Mucous membranes are highly vascular, allowing rapid entry of the drug into the systemic circulation. This route avoids first-pass metabolism and the hostile gut environment. In some cases, the drug can be delivered directly to the site of action (e.g., lungs). The drug may be delivered in a dissolvable form (suppository/pessary), mist, aerosol, or liquid to any number of sites, such as sublingual, ocular, pulmonary, intranasal, rectal, and vaginal.

Direct parenteral injection of drugs (e.g., into systemic circulation, cerebrospinal fluid, or tissue) avoids first-pass metabolism and provides rapid delivery to the site of action. The degree of vascularity affects the onset of action, with a slow onset from subcutaneous administration, an intermediate onset from intramuscular administration, and a rapid onset from intravenous administration. Parenteral administration

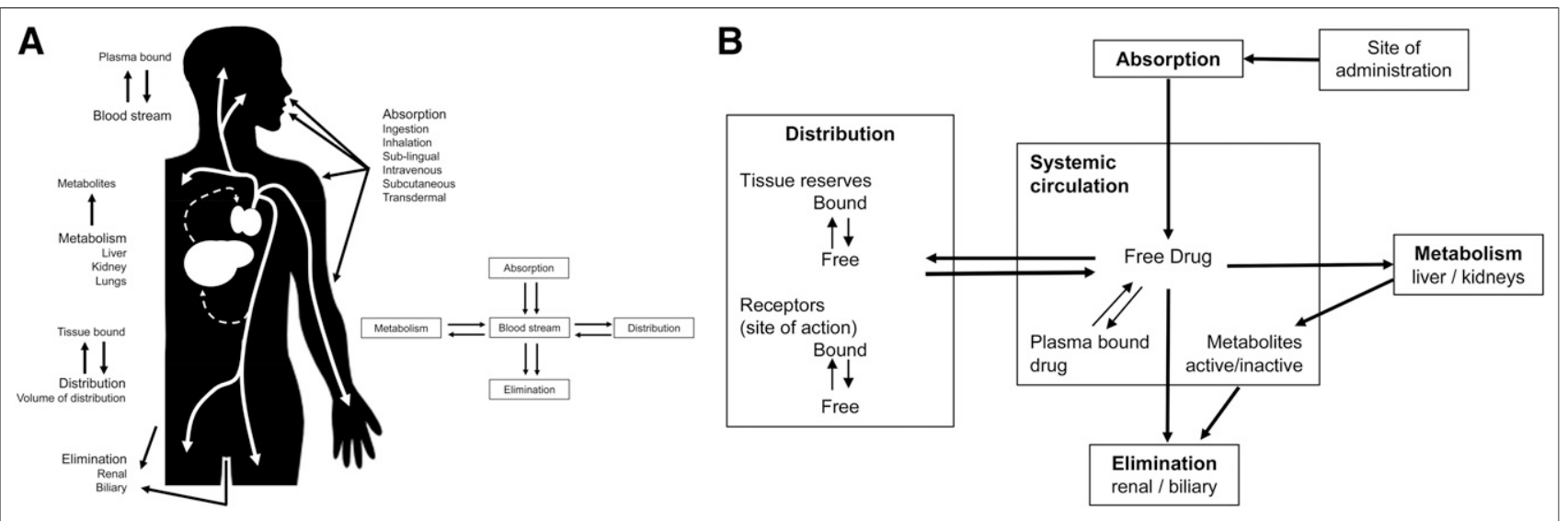

FIGURE 2. Schematic of pharmacokinetics and absorption, distribution, metabolism, and excretion concept (A), and same schematic highlighting interplay between free and bound drug, and pathway from site of administration to site of action (B). 
TABLE 1

Characteristics of Various Routes of Administration of Drugs (2-6)

\begin{tabular}{|c|c|c|}
\hline Route & Advantage & Disadvantage \\
\hline $\begin{array}{l}\text { Intranasal } \\
\text { (e.g., antihistamine) }\end{array}$ & $\begin{array}{l}\text { Rapid delivery and immediate effect. High } \\
\text { bioavailability. No first-pass metabolism. Avoids } \\
\text { gastric environment. }\end{array}$ & $\begin{array}{l}\text { Local irritation. Limited to small doses and small } \\
\text { range of drugs. }\end{array}$ \\
\hline $\begin{array}{l}\text { Sublingual } \\
\text { (e.g., nitroglycerin) }\end{array}$ & $\begin{array}{l}\text { Easy and convenient delivery. Rapid delivery and } \\
\text { immediate effect. High bioavailability. No first- } \\
\text { pass metabolism. Avoids gastric environment. } \\
\text { Self-administration. }\end{array}$ & $\begin{array}{l}\text { Changes in absorption if swallowed, chewed, or taken } \\
\text { after emesis. }\end{array}$ \\
\hline $\begin{array}{l}\text { Oral/enteral } \\
\text { (e.g., captopril) }\end{array}$ & $\begin{array}{l}\text { Easy, reliable, economic, convenient, painless, } \\
\text { no infection risk. Self-administration. }\end{array}$ & $\begin{array}{l}\text { First-pass metabolism/elimination decreases } \\
\text { bioavailability. Slow delivery and onset of action. } \\
\text { Dose form needs to accommodate gastric } \\
\text { environment (e.g., transit stomach intact for } \\
\text { small-bowel absorption). Bioavailability can be } \\
\text { influenced by changes in gut status (e.g., emesis, } \\
\text { diarrhea, or constipation). }\end{array}$ \\
\hline $\begin{array}{l}\text { Rectal } \\
\text { (e.g., laxatives) }\end{array}$ & $\begin{array}{l}\text { Rapid delivery and immediate effect. High } \\
\text { bioavailability. No first-pass metabolism. Avoids } \\
\text { gastric environment. Suitable for patients with } \\
\text { emesis or otherwise inappropriate oral route. }\end{array}$ & $\begin{array}{l}\text { Unpleasant form of administration, with bacteremia } \\
\text { risk for immunocompromised patient. Altered } \\
\text { absorption in diarrhea and constipation. }\end{array}$ \\
\hline $\begin{array}{l}\text { Inhalation } \\
\text { (e.g., albuterol) }\end{array}$ & $\begin{array}{l}\text { Rapid delivery and immediate effect. High } \\
\text { bioavailability. No first-pass metabolism. Avoids } \\
\text { gastric environment. Direct delivery to affected } \\
\text { tissues. Self-administration. }\end{array}$ & $\begin{array}{l}\text { Local irritation. Limited to small doses and small range } \\
\text { of drugs. May require special equipment and } \\
\text { decreased efficacy with incorrect use. }\end{array}$ \\
\hline $\begin{array}{l}\text { Intramuscular } \\
\text { (e.g., morphine) }\end{array}$ & $\begin{array}{l}\text { Intermediate onset of action. Suitable for oil-based } \\
\text { drugs. Easier (less skill) administration than } \\
\text { intravenous. }\end{array}$ & $\begin{array}{l}\text { Local edema, irritation, or pain. Slower onset of action. } \\
\text { Infection risk. }\end{array}$ \\
\hline $\begin{array}{l}\text { Intravenous } \\
\text { (e.g., furosemide) }\end{array}$ & $\begin{array}{l}\text { Rapid delivery and immediate effect. Is } 100 \% \\
\text { bioavailable. No first-pass metabolism. Avoids } \\
\text { gastric environment. Controlled drug delivery. }\end{array}$ & $\begin{array}{l}\text { Irritation or pain. Risk of infection. Solution must be } \\
\text { dissolved well. Risk of embolism. Action not easily } \\
\text { reversed. Rapid onset of toxicity. }\end{array}$ \\
\hline $\begin{array}{l}\text { Subcutaneous } \\
\text { (e.g., insulin) }\end{array}$ & $\begin{array}{l}\text { Slower absorption and onset of action. Suitable for } \\
\text { oil-based drugs. }\end{array}$ & $\begin{array}{l}\text { Local edema, irritation, or pain. Small volumes. Slow } \\
\text { onset of action. Infection risk. }\end{array}$ \\
\hline $\begin{array}{l}\text { Transdermal } \\
\text { (e.g., fentanyl) }\end{array}$ & $\begin{array}{l}\text { Easy, reliable, economic, convenient, painless. } \\
\text { Enables slow and prolonged drug delivery. } \\
\text { No first-pass metabolism. Avoids gastric } \\
\text { environment. Self-administration. }\end{array}$ & $\begin{array}{l}\text { Slow onset of action. Local skin reactions can occur. } \\
\text { Needs highly lipophilic drugs. }\end{array}$ \\
\hline $\begin{array}{l}\text { Percutaneous } \\
\text { (e.g., diclofenac/ } \\
\text { diclofenac sodium } \\
\text { gel) }\end{array}$ & $\begin{array}{l}\text { Easy, reliable, economic, convenient, painless. } \\
\text { Suitable for local effect. }\end{array}$ & Slow onset of action. Local skin reactions can occur. \\
\hline
\end{tabular}

affords the greatest control over drug delivery and includes intravenous, intraarterial, intramuscular, subcutaneous, intraperitoneal, and intrathecal routes.

Transdermal and percutaneous administration requires passive diffusion of highly lipophilic drugs across the skin. This approach provides a slow onset of action and the potential for slow, continuous drug delivery (e.g., nicotine patches).

\section{DISTRIBUTION}

Distribution refers to movement of the drug from the systemic circulation to tissues (2-6). The drug needs to be distributed to the site of action in sufficient concentration to generate the therapeutic action. Distribution essentially involves the circulatory system (including some minor lymphatic involvement), which distributes drugs to all tissues except brain and testes (because of membrane barriers). Consequently, relative blood flow to tissues will affect the dose required. Using simple diffusion after intravenous injection as an example, the initial high plasma concentration reaches equilibrium after rapid entry into cells with high perfusion. Poorly perfused tissues will continue to concentrate the drug and thus decrease plasma concentrations. In turn, the high concentrations of drug in well-perfused tissues will decrease the time to reach equilibrium across the membranes (Fig. 3). This principle is exploited in ${ }^{201} \mathrm{Tl}-$ based stress/redistribution myocardial perfusion studies. Given that the tissue concentration of a drug is difficult to measure, plasma concentration is used to estimate tissue concentration (6). Major factors that affect the distribution of drugs include diffusion rate, affinity of the drug to the tissues, blood flow (perfusion), and binding to plasma proteins.

An important concept to understand when discussing pharmacokinetics, and one that surfaces in radiopharmacy, is protein binding. Within the blood, a drug may have an 


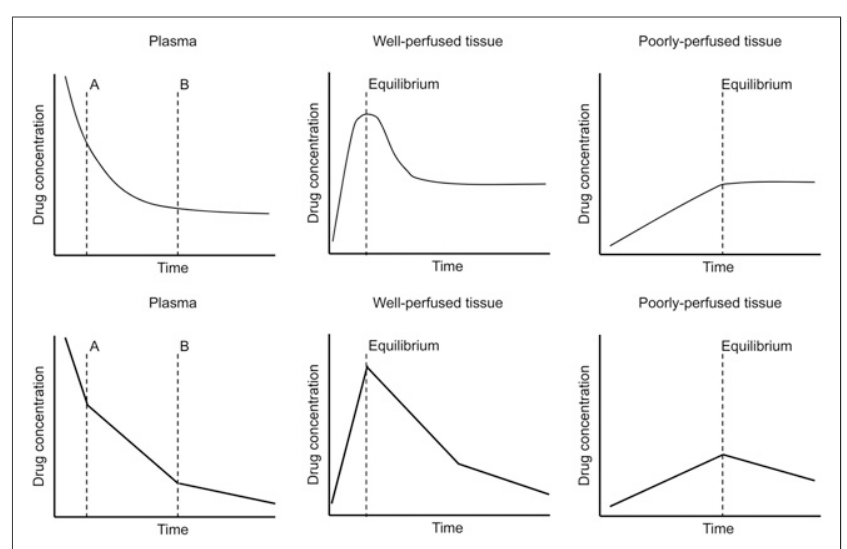

FIGURE 3. Schematics of equilibrium between drug concentration and plasma, well-perfused tissue, and poorly perfused tissue. Set of 3 schematics at top does not incorporate effects of metabolism or elimination but illustrate early equilibrium in wellperfused tissue $(A)$ followed by period of concentration in poorly perfused tissues ( $A$ to $B$ ) before reaching equilibrium in all tissues and plasma (B). Set of 3 schematics at bottom provides phases as discrete intervals (straight line) and illustrates impact of elimination. (Adapted from (3).)

affinity to plasma proteins, typically intracellular proteins, albumin, and glycoproteins $(3,6)$. The protein binding of drugs in plasma (mostly albumin) has low specificity and has no action (no potency) but forms drug-protein complexes in a similar fashion to the drug-receptor complexes previously discussed (1). Most drug-protein binding in plasma is reversible and can act as a reservoir, releasing free drug when unbound concentrations of free drug decline (Fig. 2B) (3). For drugs with a large amount of plasma protein binding (e.g., ibuprofen), equilibrium may occur between tissues and plasma, with a small fraction of the actual drug (free drug) in the body. The vast reserves of plasma protein-bound drug can provide prolonged effects through sustained release of the drug. There is, however, competition for plasma binding that can have significant implications for drug effects. For example, if ibuprofen were displaced through competition, the result would be significantly higher free drug in tissue and blood. Aspirin and warfarin compete for the same plasma protein binding sites, and thus, coadministration potentiates the effects of the two $(3,6)$. A small number of drugs may bind irreversibly to plasma proteins via covalent bonding. As a result, bound drug is not released in response to decreasing plasma or tissue concentrations. The radiopharmaceutical ${ }^{99 \mathrm{~m}} \mathrm{Tc}-$ diethylenetriaminepentaacetic acid has about $10 \%$ plasma protein binding, and this will have a minor influence on half clearance and glomerular filtration rate calculations. Conversely, ${ }^{99 \mathrm{~m}} \mathrm{Tc}$-gluconate has high protein binding ( $\left.>50 \%\right)$, which truncates pharmacokinetics. ${ }^{99 \mathrm{~m}} \mathrm{Tc}-$ mercaptoacetyltriglycine has as much as $90 \%$ plasma protein binding and so relies on tubular secretion and effective renal plasma flow (rather than glomerular filtration rate). When a drug is highly plasma protein-bound, it typically has a lower volume of distribution (6).
An important concept for pharmacokinetic principles and calculations is the volume of distribution, which is the amount of drug administered divided by the plasma concentration of the drug. This volume represents the distribution of the drug between plasma and tissue compartments $(2,3,6)$. Usually, the volume of distribution does not actually equal the real volume of the compartments; it is simply a model to help understand drug behavior. For example, a 70-kg person might be expected to have less than $70 \mathrm{~L}$ of volume throughout the body, yet a volume of distribution for a given drug might exceed several hundred liters. A volume of several hundred liters is clearly not possible in a 70-kg person but allows a theoretic understanding of drug behavior. When the volume of distribution is high, it reflects a relatively low drug concentration in plasma (minimal plasma protein binding) and extensive distribution through body tissues. It really represents an apparent volume of distribution, or the fluid volume that would be required at steady state (equilibrium) to contain the plasma-concentration-equivalent total drug amount in the body (6). The volume of distribution is used as a principle for compartment modeling and in pharmacokinetic calculations, but it is not an actual physical volume.

Compartment modeling is used in pharmacokinetics and radiopharmacy to simplify understanding of the relationship between drugs or radiopharmaceuticals and their distribution within the body. The body might be considered to comprise 4 liquid compartments: plasma water (5\%), interstitial water (16\%), intracellular water (35\%), and fat (20\%) (2). A smaller fifth compartment, transcellular water (2\%), is sometimes used and represents compartments partitioned by a barrier such as the blood-brain barrier or the testes (2). In each compartment, a drug may be present in either bound or free forms, and it is the free form that can move from one compartment to another (2). Movement between compartments can be measured and expressed as a rate constant. For simplicity and depending on what is being modeled, compartment modeling may use single, double, or multiple compartments (Fig. 4).

\section{METABOLISM}

Drug metabolism occurs largely in the liver but can also occur in the kidneys, lungs, skin, and gastrointestinal tract (6). Metabolism involves enzymes that modify the drug in various cells (e.g., for the liver, in hepatocytes) (6). Most drugs are formulated to be lipid-soluble so that they can cross the phospholipid bilayer membranes and be suitable for oral absorption. Because lipid-soluble drugs would also be reabsorbed from urine after elimination, metabolism of lipid-soluble drugs to water-soluble structures is needed for effective renal elimination (3). The concept of a prodrug was previously introduced (1). A prodrug is an inactive drug that is metabolized into an active form. Most angiotensin-converting enzyme inhibitors are prodrugs (e.g., inactive enalapril undergoes biotransformation to enalaprilat), but captopril is already in its active form.

Conversely, metabolism of active drugs relates to enzymic modification of the drug structure to render it less active (e.g., 


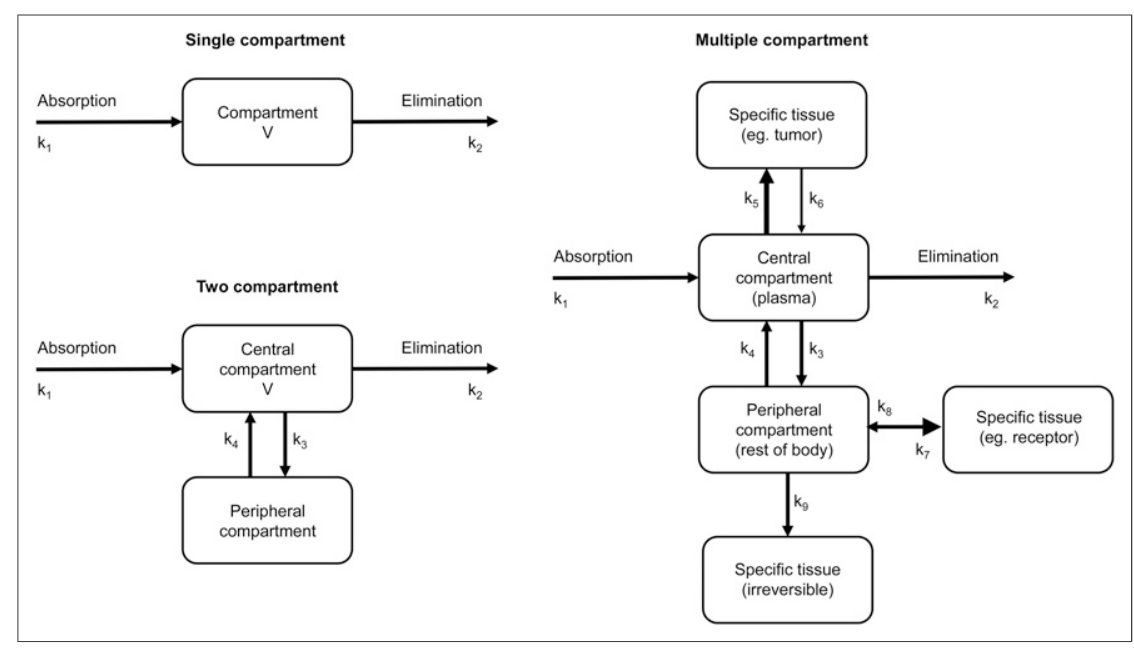

FIGURE 4. Schematic of 1-compartment model, 2-compartment model, and multicompartment model. Elimination rate constant reflects movement from one compartment or volume of distribution to another and can be calculated numerically. Schematically, rate constant may be represented in several ways. In multiple-compartment model, $\mathrm{k}_{5}$ and $k_{6}$ have arrows of different sizes, indicating greater movement of drug to tissue compartment than from it. Likewise, for $k_{7}$ and $k_{8}$, double-head arrow with different sizes of arrowhead is used to represent relative $k$ values. When drug transport between compartments is not reversible, single-head arrow is used $\left(\mathrm{k}_{\mathrm{g}}\right)$. Note that multiple methods would not be used on a single schematic as is done here. reactions-may be referred to as preconjugation. Oxidation generally adds a polar group to the chemical structure of a drug by adding an oxygen molecule, reduction tends to add a hydrogen molecule, and hydrolysis adds water. Phase II-or conjugation and hydrolysis reactions-generally facilitate attachment of the drug to a polar molecule. Either the drug or the metabolite from phase I metabolism is covalently bonded to a substrate. Some examples include glucuronidation, methylation, acetylation, and sulfation. Most drugs undergo both phase I and phase II metabolism; however, some drugs will undergo only phase I or phase II (3). Although a detailed discussion of the mechanisms of metabolism are beyond the scope of this discussion, Figure 5 provides a summary insight into the process.

\section{ELIMINATION}

Drugs and their metabolites can be aspirin becomes salicylic acid), inactive (e.g., morphine becomes inactive morphine-3-glucuronide, although a second metabolite morphine-6-glucuronide is more active), or, for most drugs, more susceptible to elimination (e.g., acetaminophen in Fig. 5) (3,6). Some drug metabolites, however, can have their own activity and, in some cases, be more active (e.g., nitroglycerin becomes the more active nitric oxide).

Modifications to drugs and prodrugs are referred to as biotransformations and can be categorized as phase I or phase II $(3,6)$. Phase I-or oxidation, reduction, and hydrolysis

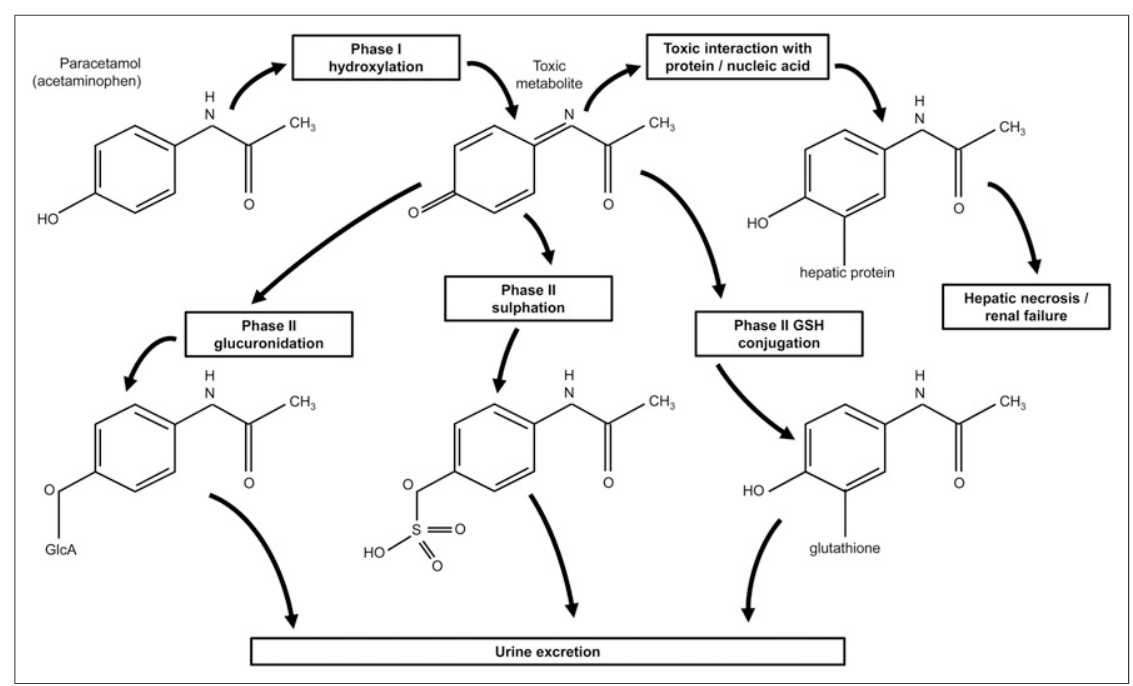

FIGURE 5. Phase I and II metabolism of acetaminophen. Phase I hydroxylation results in toxic metabolite, with 3 forms of phase II metabolism converting metabolite to a form for urine excretion. Toxic interaction can occur, leading to liver necrosis and potential renal failure, especially with deleted hepatic glutathione. (Adapted from (13).) eliminated from the body through several mechanisms and in several forms, which will be familiar to nuclear medicine professionals because the pathways are similar to those for radiopharmaceuticals $(3,6)$. Some drugs can have fractional elimination via several routes. Liquid elimination includes primarily renal and biliary (urine and bile) excretion but also excretion in sweat, tears, saliva, and breast milk. Acetaminophen is excreted via the kidneys, whereas salicylic acid (a metabolite of aspirin) can be excreted via sweat. Lidocaine is excreted via the biliary system. Caffeine and theophylline (metabolites of the prodrug aminophylline) are excreted via saliva. People can be tested for drug use through urine and saliva samples. Solid excretion occurs via the gastrointestinal tract (feces) and in hair. Differentiating fecally eliminated drugs can be confounded by biliary excretion that transits the colon and by orally administered drugs that remain unabsorbed. Nonetheless, digoxin is an example of excretion in feces via colonic lumen secretion. Drugs eliminated via the hair can be incorporated into the hair structure (e.g., codeine or morphine) or secreted onto the hair by sebum or sweat. Volatile drugs may be eliminated via gases in the lungs, with alcohol being the most common example.

There are 2 important mechanisms to briefly discuss. Renal excretion via 


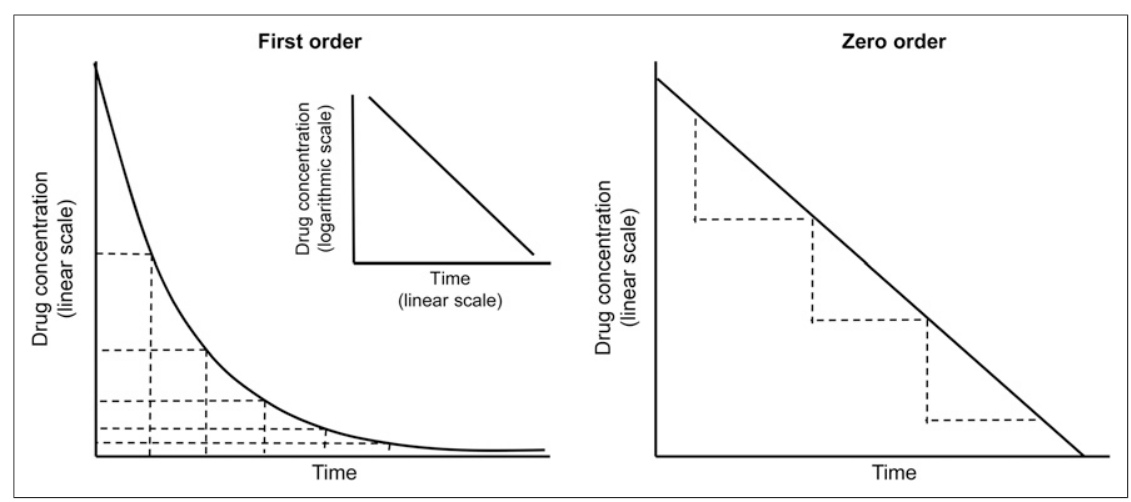

FIGURE 6. Schematic of first-order and zero-order elimination. First-order elimination follows exponential trend and can be displayed with logarithmic $y$-axis to generate straight line (inset). Zero-order elimination removes constant amount of drug per unit time. constant (exponential) fraction of drug is eliminated per unit of time and is similar in concept to radioactive decay (Fig. 6). In theory, the amount of drug present never reaches zero. The fourth, zero-order kinetics, is when there is a constant (linear) rate of drug elimination, indicating that the rate of elimination is independent of drug concentration. Unlike first-order kinetics, a constant amount of drug is eliminated per unit of time and the drug present will reach zero (Fig. 6).

\section{KINETICS}

Perhaps the best way to demonstrate glomeruli filtration may be followed by tubular reabsorption to retain key nutrients and other substances (e.g., amino acids and vitamins) $(3,6)$. Some drugs may also pass back into the circulation via reabsorption. Similarly, drugs eliminated via the biliary system may be reabsorbed back from the intestines and returned via the hepatic portal vein (enterohepatic cycle) $(3,6)$. In both circumstances, the effective duration of the drug effect is prolonged.

Elimination of drugs from the plasma introduces 4 important quantitative concepts (2-6). The first, clearance, is the rate of elimination of the drug from the body and is the product of the elimination rate constant and the volume of distribution. The second, half clearance time, is the time required for the amount of drug present to be reduced by $50 \%$. This can be a measure of plasma half-life or totalbody half-life. The third, first-order kinetics, is when a an understanding of pharmacokinetics is mathematically. The calculations are simple for those in nuclear medicine, as there are parallels with several other equations used in the field. Presented below are several scenarios that are designed to highlight applications of pharmacokinetic calculations (Table 2). Of course, these applications are only examples, and the methods of calculation can readily be adapted for other scenarios.

In scenario 1 , consider a patient weighing $70 \mathrm{~kg}$ who is given an intravenous bolus injection of $25 \mathrm{mg}$ of a drug. If plasma concentrations after injection are as per Table 3, the elimination rate constant and half-life can be readily calculated. The first step would be to plot the data on semilogarithmic scales to demonstrate a straight line, confirming first-order kinetics. Rather than use the slope of the line (Fig. 7A) for subjective calculations or estimates, it is easier

TABLE 2

Summary of Useful Formulae and Definitions

\begin{tabular}{|c|c|c|}
\hline Use & Equation & Definition \\
\hline \multirow[t]{4}{*}{ Drug concentration } & $\mathrm{C}=\mathrm{C}_{0} \mathrm{e}^{-\mathrm{kt}}$ & $\mathrm{C}=$ drug concentration at time $\mathrm{t}$ after $\mathrm{C}_{0}$ \\
\hline & & $\mathrm{C}_{0}=$ drug concentration at reference time \\
\hline & & $\mathrm{k}=$ elimination rate constant \\
\hline & & $\mathrm{t}=$ time between $\mathrm{C}$ and $\mathrm{C}_{0}$ \\
\hline \multirow[t]{3}{*}{ Elimination rate constant } & $\mathrm{k}=\ln 2 / \mathrm{T}_{0.5}$ & $\mathrm{k}=$ elimination rate constant \\
\hline & & $\ln 2=0.693$ \\
\hline & & $\mathrm{T}_{0.5}=$ half clearance time \\
\hline \multirow[t]{2}{*}{ Volume of distribution } & $\mathrm{V}=$ amount in body $(\mu \mathrm{g}) /$ actual $\mathrm{C}_{0}$ & $\mathrm{~V}=$ volume of distribution \\
\hline & & $\begin{array}{l}\text { Actual } \mathrm{C}_{0}=\text { concentration at time of } \\
\text { administration }\end{array}$ \\
\hline \multirow[t]{5}{*}{ Area under curve } & $\mathrm{AUC}_{0-\infty}=\mathrm{FD} / \mathrm{Nk}$ & $\begin{array}{l}\mathrm{AUC}_{0-\infty}=\text { area under curve (total drug dose) } \\
\text { from time } 0 \text { to infinity }\end{array}$ \\
\hline & & $F=$ fraction of drug absorbed \\
\hline & & $\mathrm{D}=$ dose \\
\hline & & $\mathrm{V}=$ volume of distribution \\
\hline & & $\mathrm{k}=$ elimination rate constant \\
\hline \multirow[t]{3}{*}{ Clearance } & $\mathrm{CL}=\mathrm{k} \times \mathrm{V}$ & $\mathrm{CL}=$ clearance \\
\hline & & $\mathrm{k}=$ elimination rate constant \\
\hline & & $\mathrm{V}=$ volume of distribution \\
\hline \multirow[t]{3}{*}{ Time to maximum concentration } & $\mathrm{T}_{\max }=\left(1 /\left[\mathrm{k}_{\mathrm{a}}-\mathrm{k}\right]\right) \ln \left(\mathrm{k}_{\mathrm{a}} / \mathrm{k}\right)$ & $\mathrm{T}_{\max }=$ time to maximum concentration \\
\hline & & $\mathrm{k}_{\mathrm{a}}=$ absorption rate constant \\
\hline & & $\mathrm{k}=$ elimination rate constant \\
\hline
\end{tabular}


TABLE 3

Data for First Scenario

\begin{tabular}{lc}
\hline Time $(\mathrm{h})$ & Plasma concentration $(\mu \mathrm{g} / \mathrm{L})$ \\
\hline 2 & 139.0 \\
4 & 65.6 \\
6 & 31.1 \\
8 & 14.6 \\
\hline
\end{tabular}

to use the following equation, where $\mathrm{C}$ is the drug concentration at a given time, $\mathrm{C}_{0}$ is the drug concentration at the reference time, $\mathrm{k}$ is the elimination rate constant, and $\mathrm{t}$ is time between the drug concentration at a given time and the drug concentration at the reference time:
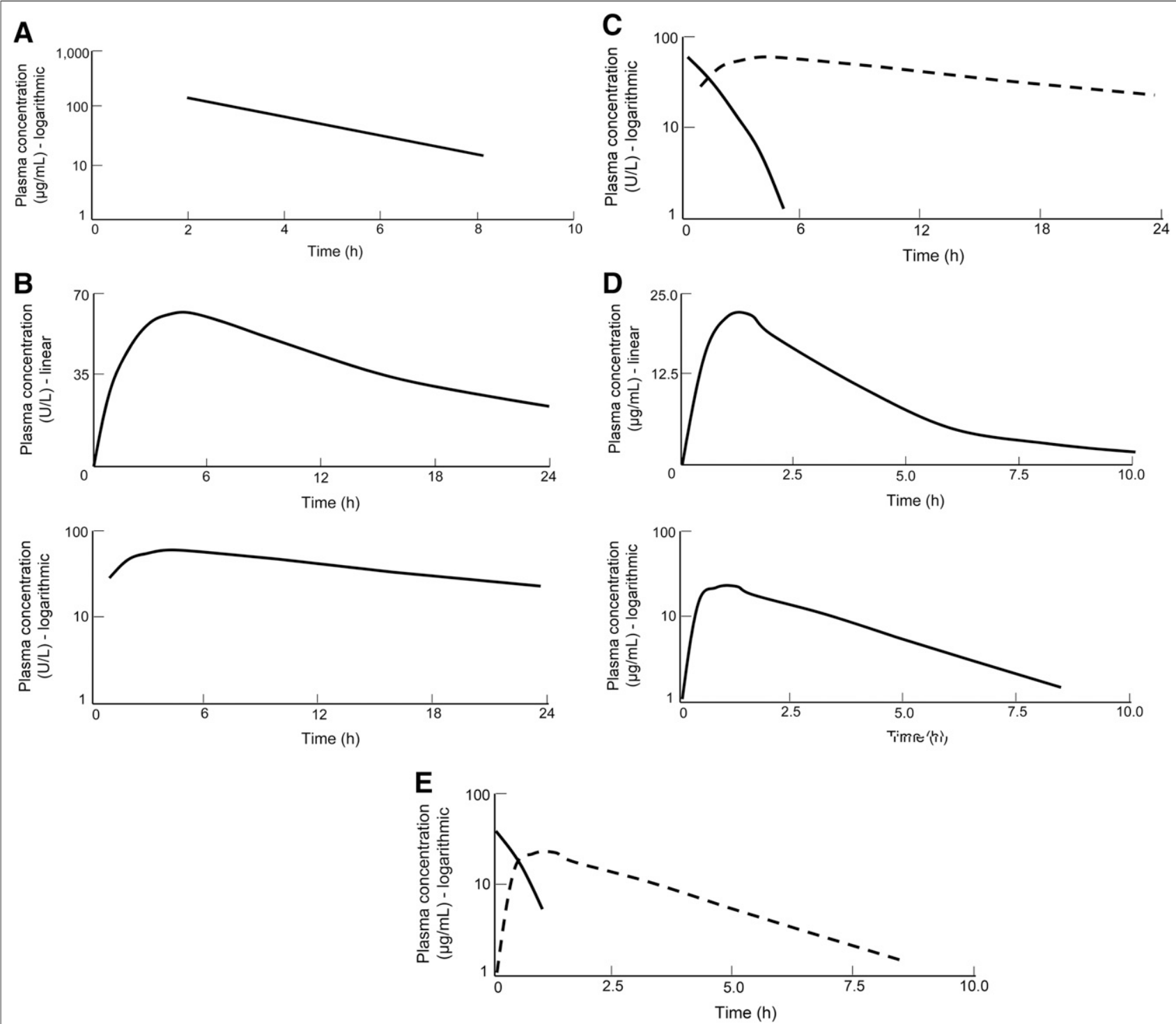

FIGURE 7. (A) Logarithmic/linear plot confirming single-compartment monoexponential curve (scenario 1). (B) Linear/linear and logarithmic/linear plots demonstrating interplay between absorption and elimination for scenario 2 (scenario 2). (C) Logarithmic/ linear plots for raw data (dashed line) and for $\mathrm{R}$ (scenario 2). (D) Linear/linear and logarithmic/linear plots demonstrating interplay between absorption and elimination for scenario 3 (scenario 3). (E) Logarithmic/linear plots for raw data (dashed) and for elimination curve minus plasma curve (R) (solid line) (scenario 3). 
Although the origin (the drug concentration at administration) can be estimated to determine the theoretic blood concentration at administration by reading the plot, a more accurate method (given that the elimination rate constant has been determined) is simply to use the following calculation:

$$
\begin{aligned}
\mathrm{C} & =\mathrm{C}_{0} \mathrm{e}^{-\mathrm{kt}} \\
139 & =\mathrm{C}_{0} \mathrm{e}^{-0.3745 \times 2} \\
139 & =\mathrm{C}_{0} \times 0.4728 \\
\mathrm{C}_{0} & =139 / 0.4728 \\
\mathrm{C}_{0} & =294
\end{aligned}
$$

Thus,

$$
\begin{aligned}
& \mathrm{V}=25,000 / 294 \\
& \mathrm{~V}=85 \mathrm{~L}
\end{aligned}
$$

The area under the curve (AUC) from the time of administration to infinity $\left(\mathrm{AUC}_{0-\infty}\right)$ can be used to calculate the total drug burden, where $\mathrm{F}$ is the fraction of the drug absorbed (100\% for intravenous) and D is the dose $(\mu \mathrm{g})$ :

$$
\begin{aligned}
& \mathrm{AUC}_{0-\infty}=\mathrm{FD} / \mathrm{Vk} \\
& \mathrm{AUC}_{0-\infty}=25,000 \mu \mathrm{g} /(85 \times 0.3745) \\
& \mathrm{AUC}_{0-\infty}=25,000 / 31.8325 \\
& \mathrm{AUC}_{0-\infty}=785.36 \mu \mathrm{g} \text { or } 0.785 \mathrm{mg} \mathrm{h} / \mathrm{L}
\end{aligned}
$$

Clearance can be readily calculated as

$$
\begin{aligned}
& \text { Clearance }=\mathrm{k} \times \mathrm{V} \\
& \text { Clearance }=0.3745 \times 85 \\
& \text { Clearance }=31.83 \mathrm{~L} / \mathrm{h}
\end{aligned}
$$

Scenario 2 considers a more complex problem. Drug concentrations of interest may include tissues (other than the plasma compartment) or plasma concentrations but without the advantage of the immediate absorption associated with intravenous administration (e.g., oral). In these cases, both absorption and the absorption rate constant need to be considered rather than just elimination. Consider the plasma concentrations in arbitrary units of an orally administered drug in Table 4. Graphing these data does not yield the monoexponential curve expected of first-order kinetics, because of the overlapping influence of absorption and elimination (Fig. 7B). The logarithmic plot does, however, demonstrate a late section with a straight line from $7 \mathrm{~h}$ onward. This section, being minimally affected by absorption, can be used to determine the elimination rate constant and half clearance time:

$$
\begin{aligned}
\mathrm{C} & =\mathrm{C}_{0} \mathrm{e}^{-\mathrm{kt}} & & \mathrm{k}=\ln 2 / \mathrm{T}_{0.5} \\
25.3 & =58.1 \mathrm{e}^{-\mathrm{k} \times 17} & \mathrm{~T}_{0.5} & =\ln 2 / \mathrm{k} \\
25.3 / 58.1 & =\mathrm{e}^{-\mathrm{k} \times 17} & \mathrm{~T}_{0.5} & =0.693 / 0.0489 \\
\ln 0.4355 & =-\mathrm{k} \times 17 & \mathrm{~T}_{0.5} & =14.17 \mathrm{~m} \\
\mathrm{k} & =0.0489 \mathrm{~m}^{-1} & &
\end{aligned}
$$

To determine the absorption rate constant, a process known as curve stripping is required. Using the elimination rate

Data for Second Scenario

\begin{tabular}{lc}
\hline Time $(\mathrm{min})$ & Plasma concentration $(\mathrm{U} / \mathrm{L})$ \\
\hline 0 & 0 \\
1 & 31.3 \\
2 & 49.3 \\
3 & 58.6 \\
4 & 62.5 \\
5 & 62.8 \\
7 & 58.1 \\
10 & 50.6 \\
16 & 36.1 \\
24 & 25.3 \\
\hline
\end{tabular}

constant determined above and the data from $7 \mathrm{~h}$ onward (Table 5), one can apply the equation to determine the value for each time interval projected back along the elimination line (bold figures in Table 5), in effect stripping away the influence of absorption. For example, times 1, 3, and $5 \mathrm{~h}$ can be calculated, respectively, as

$$
\begin{array}{rlrl}
\mathrm{C}= & \mathrm{C}_{\mathrm{t}} \mathrm{e}^{-\mathrm{kt}} & \mathrm{C} & =\mathrm{C}_{\mathrm{t}} \mathrm{e}^{-\mathrm{kt}} \\
25.3 & =\mathrm{C}_{1} \mathrm{e}^{-0.0489 \times 23} & 25.3 & =\mathrm{C}_{3} \mathrm{e}^{-0.0489 \times 21} \\
25.3 & =\mathrm{C}_{1} \times 0.3247 & 25.3 & =\mathrm{C}_{3} \times 0.3581 \\
\mathrm{C}_{1}= & 77.92 & \mathrm{C}_{3} & =70.65 \\
\mathrm{C} & =\mathrm{C}_{\mathrm{t}} \mathrm{e}^{-\mathrm{kt}} & & \\
25.3 & =\mathrm{C}_{5} \mathrm{e}^{-0.0489 \times 19} & \\
25.3 & =\mathrm{C}_{5} \times 0.3949 \\
\mathrm{C} 5 & =64.06 & &
\end{array}
$$

Subtraction of the plasma values from the eliminationcurve values generates a value, $\mathrm{R}$, which can be added to the table of data (Table 5). Graphing $\mathrm{R}$ on a logarithmic plot (Fig. 7C) generates an absorption rate. It is worth noting that the absorption line may not be a straight line representing a second compartment associated with distribution (e.g., vascular and extravascular). Although one should not assume a straight line for absorption in calculations, it offers a practical approach. In this particular case, there is a straight-line

TABLE 5

Use of Data for 7- to 24-Hour Stable Elimination Period to Calculate Elimination Rate Constant and Backproject Elimination Curve by Calculating Earlier Values (Bold) for Elimination Confounded by Absorption

\begin{tabular}{cccc}
\hline $\begin{array}{c}\text { Time } \\
(\mathrm{h})\end{array}$ & $\begin{array}{c}\text { Plasma } \\
\text { concentration } \\
(\mathrm{U} / \mathrm{L})\end{array}$ & $\begin{array}{c}\text { Elimination } \\
\text { curve } \\
\text { concentration }\end{array}$ & $\begin{array}{c}\mathrm{R} \text { (elimination - } \\
\text { plasma) }\end{array}$ \\
\hline 0 & 0 & $\mathbf{8 1 . 8}$ & $\mathbf{8 1 . 8}$ \\
1 & 31.3 & $\mathbf{7 7 . 9}$ & $\mathbf{4 6 . 6}$ \\
\hline 2 & 49.3 & $\mathbf{7 4 . 0}$ & $\mathbf{2 4 . 7}$ \\
3 & 58.6 & $\mathbf{7 0 . 7}$ & $\mathbf{1 2 . 1}$ \\
4 & 62.5 & $\mathbf{6 7 . 1}$ & $\mathbf{4 . 6}$ \\
5 & 62.8 & $\mathbf{6 4 . 1}$ & $\mathbf{1 . 3}$ \\
7 & 58.1 & 58.1 & \\
10 & 50.6 & 50.6 & \\
16 & 36.1 & 36.1 & \\
24 & 25.3 & 25.3 & \\
\hline
\end{tabular}


relationship between time 0 and $3 \mathrm{~h}$ that can be used for accurate calculations. Thus, the absorption rate constant $\left(\mathrm{k}_{\mathrm{a}}\right)$ can be determined as

$$
\begin{aligned}
\mathrm{C} & =\mathrm{C}_{0} \mathrm{e}^{-\mathrm{ka} \times \mathrm{t}} \\
12.1 & =46.6 \mathrm{e}^{-\mathrm{ka} \times 2} \\
12.1 / 46.6 & =\mathrm{e}^{-\mathrm{ka} \times 2} \\
\ln 0.2596 & =-\mathrm{k}_{\mathrm{a}} \times 2 \\
\mathrm{k}_{\mathrm{a}} & =0.6742 \mathrm{~m}^{-1}
\end{aligned}
$$

With both the elimination and the absorption rate constants now calculated, the time to peak concentration $\left(\mathrm{T}_{\max }\right)$ can be calculated as

$$
\begin{aligned}
& \mathrm{T}_{\max }=\left(1 /\left[\mathrm{k}_{\mathrm{a}}-\mathrm{k}\right]\right) \ln \left(\mathrm{k}_{\mathrm{a}} / \mathrm{k}\right) \\
& \mathrm{T}_{\max }=(1 /[0.6742-0.0489]) \ln (0.6742 / 0.0489) \\
& \mathrm{T}_{\max }=(1 /[0.6742-0.0489]) \ln (13.8) \\
& \mathrm{T}_{\max }=1.6 \times 2.6 \\
& \mathrm{~T}_{\max }=4.2 \mathrm{~m}
\end{aligned}
$$

The third scenario is a more complex opportunity to incorporate AUC calculations. Consider the data in Table 6. After subcutaneous injection of a drug with a dose of 7.5 $\mathrm{mg} / \mathrm{kg}$, plasma concentrations in blood were monitored (in $\mu \mathrm{g} / \mathrm{mL}$ ). The data can be plotted (Fig. 7D) and the straightline portion of the logarithmic curve used to determine both the elimination rate constant and, subsequently, the backprojected values for the elimination curve as per scenario 2 (Table 7). The elimination rate constant is calculated as

$$
\begin{aligned}
\mathrm{C} & =\mathrm{C}_{0} \mathrm{e}^{-\mathrm{kt}} \quad \mathrm{T}_{0.5}=\ln 2 / \mathrm{k} \\
3.2 & =11 \mathrm{e}^{-\mathrm{k} \times 4} \quad \mathrm{~T}_{0.5}=\ln 2 / 0.3087 \\
\mathrm{k} & =0.3087 \mathrm{~h}^{-1} \mathrm{~T}_{0.5}=2.25 \mathrm{~h}
\end{aligned}
$$

Subtraction of the plasma values from the elimination-curve values generates the previously introduced value, $R$, which can be added to the table of data (Table 7). Graphing $\mathrm{R}$ on a logarithmic plot (Fig. 7E) generates an absorption curve. Thus, the absorption rate constant can be determined as

$$
\begin{aligned}
\mathrm{C} & =\mathrm{C}_{0} \mathrm{e}^{-\mathrm{k}_{\mathrm{a}} \times \mathrm{t}} \\
5.8 & =37.8 \mathrm{e}^{-\mathrm{k}^{\times 1}} \\
\mathrm{k}_{\mathrm{a}} & =1.8744 \mathrm{~h}^{-1}
\end{aligned}
$$

AUC is a valuable metric in pharmacokinetics. Several methods are available to determine the total AUC when

TABLE 6

Data for Third Scenario

\begin{tabular}{lc}
\hline Time $(\mathrm{h})$ & Plasma concentration $(\mu \mathrm{g} / \mathrm{mL})$ \\
\hline 0 & 0 \\
0.5 & 16.0 \\
1 & 22.0 \\
1.5 & 22.0 \\
2 & 19.0 \\
4 & 11.0 \\
6 & 5.6 \\
8 & 3.2 \\
\hline
\end{tabular}

TABLE 7

Use of Data for 2- to 8-Hour Stable Elimination Period to Calculate Elimination Rate Constant and Backproject Elimination Curve by Calculating Earlier Values (Bold) for Elimination Confounded by Absorption

\begin{tabular}{lccc}
\hline $\begin{array}{c}\text { Time } \\
(\mathrm{h})\end{array}$ & $\begin{array}{c}\text { Plasma } \\
\text { concentration } \\
(\mu \mathrm{g} / \mathrm{mL})\end{array}$ & $\begin{array}{c}\text { Elimination } \\
\text { curve } \\
\text { concentration }\end{array}$ & $\begin{array}{c}\mathrm{R} \text { (elimination } \\
- \text { plasma) }\end{array}$ \\
\hline 0 & 0 & $\mathbf{3 7 . 8}$ & $\mathbf{3 7 . 8}$ \\
0.5 & 16 & $\mathbf{3 2 . 4}$ & $\mathbf{1 6 . 4}$ \\
1 & 22 & $\mathbf{2 7 . 8}$ & $\mathbf{5 . 8}$ \\
1.5 & 22 & & \\
2 & 19 & 19 & \\
4 & 11 & 11 & \\
6 & 5.6 & 5.6 & \\
8 & 3.2 & 3.2 & \\
\hline
\end{tabular}

absorption and elimination phases need to be accommodated; most tend to be unnecessarily complex or inaccurate because of estimation errors. The total AUC represents the total drug dose or drug burden. An understanding of mathematics provides both greater accuracy and simplification. This method relies on an accurate determination of the absorption rate constant. It also assumes accurate calculation of the elimination rate constant and then the drug concentration in plasma at the reference time. The mathematics above indicate that the AUC is simply the area prescribed by the absorption rate constant subtracted from the area prescribed by the elimination rate constant. Thus, AUC can be calculated as

$$
\begin{aligned}
& \mathrm{AUC}=\left[\mathrm{C}_{0} / \mathrm{k}\right]-\left[\mathrm{C}_{0} / \mathrm{k}_{\mathrm{a}}\right] \\
& \mathrm{AUC}=[37.8 / 0.3087]-[37.8 / 1.8744] \\
& \mathrm{AUC}=122.45-20.17 \\
& \mathrm{AUC}=102.28 \mu \mathrm{g}
\end{aligned}
$$

These tools have many applications for problem-solving or better understanding drug or radiopharmaceutical behavior. To avoid duplication, not all parameters were calculated in each scenario; however, they could be calculated if appropriate. The parallels between these calculations and those used to problem-solve in radiopharmacy are apparent.

\section{EFFECTS OF AGING AND DISEASE}

Changes in physiology occur with disease and aging and can affect drug pharmacokinetics $(10,11)$. Older people can also have altered responses to drugs due to changes in mechanical responses, receptor mechanisms, homeostatic changes, and central nervous system function (12). It is worth considering that older patients are disproportionately represented in the nuclear medicine patient cohort and that older patients also have a higher use of medications - in particular, the use of multiple and concurrent medications (polypharmacy). Older patients or patients with disease have a less homogeneous response to medications that makes responses difficult to predict. With aging and disease come altered absorption (e.g., slower gut 
absorption of captopril); changed biodistribution (e.g., doubled volume of diazepam distribution); altered metabolism, especially with liver function changes or disease (e.g., decreased for ibuprofen); and altered elimination (e.g., nearly tripled half clearance of diazepam) (9-12). Decreases or increases in bioavailability (e.g., increased digoxin toxicity) may result from any of these factors.

\section{CONCLUSION}

Pharmacokinetics, the study of how drugs are affected by their navigation through the body, has principles that translate to radiopharmaceuticals as well. Pharmacokinetics provides essential insights into the behavior of interventional and adjunctive medications in the nuclear medicine patient. These principles provide the tools to problem-solve both practically and quantitatively. This article completes the foundational understanding of pharmacology on which specific applications will be built in subsequent articles.

\section{DISCLOSURE}

No potential conflict of interest relevant to this article was reported.

\section{REFERENCES}

1. Currie G. Pharmacology, part 1: introduction to pharmacology and pharmacodynamics. J Nucl Med Technol. 2018;46:81-86.

2. Rang H, Dale M, Ritter J, Flower R. Rang and Dale's Pharmacology. 6th ed. London, U.K.: Churchill Livingston; 2008.

3. Waller D, Renwick A, Hillier K. Medical Pharmacology and Therapeutics. 2nd ed. London, U.K.: Elsevier; 2006.

4. Bryant B, Knights K, Salerno E. Pharmacology for Health Professionals. 2nd ed. Sydney, Australia: Mosby Elsevier; 2007.

5. Greenstein B. Rapid Revision in Clinical Pharmacology. New York, NY: Radcliffe Publishing; 2008.

6. Golan DE, Tashjian AH, Armstrong EJ, Armstrong AW. Principles of Pharmacology: The Pathophysiologic Basis of Drug Therapy. 3rd ed. Philadelphia, PA: Lippincott, Williams \& Wilkins; 2012.

7. Currie GM, Wheat J, Wang L, Kiat H. Pharmacology in nuclear cardiology. Nucl Med Commun. 2011;32:617-627.

8. Jambhekar SS, Breen PJ. Basic Pharmacokinetics. London, U.K.: Pharmaceutical Press; 2009.

9. Currie GM, Kiat H, Wheat J. Pharmacokinetic considerations for digoxin in older people. Open Cardiovasc Med J. 2011;5:130-135.

10. Cusack BJ. Pharmacokinetics in older persons. Am J Geriatr Pharmacother. 2004;2:274-302.

11. Delafuente JC. Pharmacokinetic and pharmacodynamic alterations in the geriatric patient. Consult Pharm. 2008;23:324-334.

12. El Desoky ES. Pharmacokinetic-pharmacodynamic crisis in the elderly. Am J Ther. 2007;14:488-498.

13. Heard KJ. Acetylcysteine for acetaminophen poisoning. N Engl J Med. 2008; 359:285-292. 